\title{
APLIKASI PENERIMAAN SISWA BARU BERBASIS WEB (SMK Negeri 3 Yogyakarta)
}

\author{
${ }^{1)}$ Nur Heri Cahyana, ${ }_{1,23)}^{2)}$ ko Yuli Prasetyo, ${ }^{3)}$ Hidayatulah Himawan \\ ${ }^{1,2,3)}$ Prodi. Teknik Informatika \\ Universitas Pembangunan Nasional "Veteran" Yogyakarta \\ Tambakbayan 2 Babarsari, Yogyakarta \\ email : ${ }^{1)}$ dsnurheri@gmail.com
}

\begin{abstract}
Registration problems that are still using the form that led to long queues so that the assessors of prospective students are often hassles, besides the highest and lowest value of UAS as a reference the admissibility of a prospective new students can only be seen by visiting directly. So here was made Applications Web-Based Admission to solve the above problems. Based on the background of the issues above, it will build a system of Admission Selection System Based Web by using a linear sequential software development (waterfall), which has several stages including software requirements analysis phase, the design phase, the code generation phase, phase testing, and maintenance phases., so that the resulting applications have advantages in data processing. In this application also can map the school, where the making of the map using Google Maps to produce a map that has a location corresponding to the location of the original condition.
\end{abstract}

Keywords: Admission, Web, Linear Sequential Software Development

Permasalah yang terjadi pada masa pendaftaran adalah masih digunakannya formulir, yang menyebabkan antrian panjang, sehingga calon mahasiswa sering kerepotan, selain nilai tertinggi dan terendah UAS sebagai acuan diterimanya dari calon siswa baru hanya bisa dilihat dengan mengunjungi langsung. Jadi di sini dibuat Aplikasi Pendaftaran Berbasis Web untuk memecahkan masalah di atas. Berdasarkan latar belakang masalah di atas, maka dibangun sistem Penerimaan Seleksi Berbasis Web dengan menggunakan pengembangan perangkat lunak sekuensial linier (air terjun), yang memiliki beberapa tahapan, termasuk persyaratan perangkat lunak tahap analisis, tahap desain, tahap pembuatan kode, tahap pengujian, dan tahap pemeliharaan., sehingga dihasilkan aplikasi memiliki keunggulan dalam pengolahan data. Dalam aplikasi ini juga dapat memetakan sekolah, tempat pembuatan peta menggunakan Google Maps untuk menghasilkan peta yang memiliki lokasi sesuai dengan lokasi dari kondisi aslinya.

Kata kunci : Penerimaan, Web, Pengembangan Perangkat Lunar Sekuensial Linear

\section{PENDAhULUAN}

Lingkungan kegiatan penerimaan siswa baru merupakan lingkungan kegiatan rutin yang dilaksanakan oleh instansi penyelenggara pendidikan di setiap tahunnya, kenyataan dilapangan menyebutkan bahwa beberapa instansi pendidikan kurang siap dalam penyelenggaraan penerimaan siswa baru. ruwetnya masalah administrasi yang bersifat pengguna berbuntut pada kurang efisiensi dilingkungan kegiatan penerimaan siswa baru. seiring kemajuan teknologi informasi, nilai penerimaan siswa baru sudah dapat dilaksanakan secara online, ini memudahkan instansi pendidikan dan juga para pendaftar tentunya.pendaftaran siswa baru yang dapat dipantau setiap saat secaran online. Penelitian ini mengembangkan aplikasi untuk web pendaftaran siswa baru secara online menggunakan bahasa pemrograman php dan xampp sebagai web server yang di dalamnya memuat apache, ditambahkan Basis Data Oracle $10 \mathrm{~g}$. aplikasi untuk ditujukan agar dapat proses yang meliputi nilai akhir siswa baru dapat ditingkatkan dan lebih efisien pengerjaannya. 
SMK Negeri 3 Yogyakarta merupakan salah satu sekolah kejuruan di wilayah kota Yogyakarta yang berlokasi di wilayah Jetis. SMK Negeri 3 Yogyakarta ini memiliki 8 jurusan yang berbeda-beda, seperti Mesin, Listrik, Bangunan, dan lain-lain. Dengan adanya penerimaan siswa baru berbasis web diharapkan dapat memudahkan para calon pendaftar untuk melakukan pendaftaran dan mencari informasi tentang sekolah yang dituju. Selain itu dengan adanya penerimaan siswa baru web hasil dari seleksi pendaftaran dapat dilihat dengan cepat.

\section{BAHAN DAN METODE}

\subsection{Sistem Informasi}

Perangkat lunak aplikasi adalah suatu subkelas perangkat lunak komputer yang memanfaatkan kemampuan komputer langsung untuk melakukan suatu tugas yang diinginkan pengguna. Biasanya dibandingkan dengan perangkat lunak sistemyang mengintegrasikan berbagai kemampuan komputer.

Sistem Informasi merupakan sekumpulan elemen yang bekerja secara bersama-sama baik secara manual ataupun berbasis komputer dalam melaksanakan pengolahan data berupa pengumpulan, penyimpanan, pemrosesan data, untuk menghasilakan informasi yang bermakna dan berguna bagi proses pengambilan keputusan (Daihani, 2001).

\subsection{Basis Data}

Data adalah catatan atas kumpulan fakta (Vardiansyah,2008). Data merupakan bentuk jamak dari "datum", berasal dari bahasa Latin yang berarti "sesuatu yang diberikan". Dalam penggunaan sehari-hari data berarti suatu pernyataan yang diterima secara apa adanya. Pernyataan ini adalah hasil pengukuran atau pengamatan suatu variabel yang bentuknya dapat berupa angka, kata-kata, atau citra.

Sistem Basis Data adalah suatu sistem menyusun dan mengelola record-record menggunakan computer untuk menyimpan atau merekam serta memelihara data operasional lengkap sebuah organisasi/perusahaan sehingga mampu menyediakan informasi yang optimal yang diperlukan pemakai untuk proses mengambil keputusan. Salah satu cara menyajikan data untuk mempermudah modifikasi adalah dengan cara pemodelan data.

\subsection{Metode Sekuensial Linier (Waterfall)}

Metode sekuensial linier atau yang sering disebut juga dengan "siklus kehidupan klasik" atau "model air terjun" mengusulkan sebuah pendekatan kepada perkembangan perangkat lunak yang sistematik dan sekuensial yang mulai pada tingkat dan kemajuan sistem pada seluruh analisis, desain, kode, pengujian, dan pemeliharaan (Pressman, 2002). Berikut ini adalah tahapan-tahapan dalam metode sekuensial linier:

1. Analisis kebutuhan perangkat lunak,

2. Perancangan (Desain),

3. Coding (Penulisan Program),

4. Pengujian,

5. Pemeliharaan.

\subsection{Oracle 10g Express Edition Database Manager}

Oracle Corporation adalah salah satu perusahaan pembuat software yang terkenal khususnya pada database software. Perusahaan ini telah mengeluarkan banyak versi dari software mulai dari oracle $6.0,8 \mathrm{i}, 9 \mathrm{i}$ hingga $10 \mathrm{~g}$. Produk produk tersebut biasa digunakan pada skala perusahaan, yang tentu saja harganya tidak murah bagi pengguna individual. Tetapi oracle memberikan solusi untuk hal tersebut, Oracle Express Edition merupakan versi freeware yang ditujukan bagi pemula atau pengguna individual yang ingin mempelajari oracle tanpa harus mengeluarkan biaya besar atau membajak software tersebut. Versi ini memiliki banyak kesamaan dengan versi $10 \mathrm{~g}$ sehingga tidak perlu khawatir bahwa fitur yang nanti dipelajari dan digunakan di versi Express Edition tidak akan ditemukan di versi $10 \mathrm{~g}$ Enterprise (Nugroho, 2008)

\subsection{Analisis Sistem}

Sistem seleksi pendaftaran siswa baru yang akan dibangun ini merupakan suatu sistem informasi yang berbasis web dengan memanfaatkan pengambilan keputusan sederhana yang 
berfungsi sebagai alat bantu sistem untuk menentukan kelulusan atau diterima tidaknya calon siswa baru pada salah satu jurusan yang telah di pilih. Sistem dirancang dengan tujuan untuk memudahkan calon siswa baru dalam mencari informasi mengenai sekolah dan melakukan pendaftaran sesuai dengan jurusan yang telah mereka pilih. Selain itu sistem juga memudahkan admin dalam melakukan pendataan dan penilaian terhadap para calon siswa baru

\subsection{Rancangan Sistem}

Tujuan utama dari perancangan sistem secara umum adalah memberikan gambaran tentang sistem yang akan dibangun serta memahami alur informasi dan proses yang ada dalam sistem.ditunjukan dalam perancangan arsitektur gambar 1 .

Untuk menggambarkan perpindahan data dalam proses-proses suatu apliksi, baik berupa data yang masuk maupun data yang keluar dari sistem.dapat dilihat pada gambar 2.

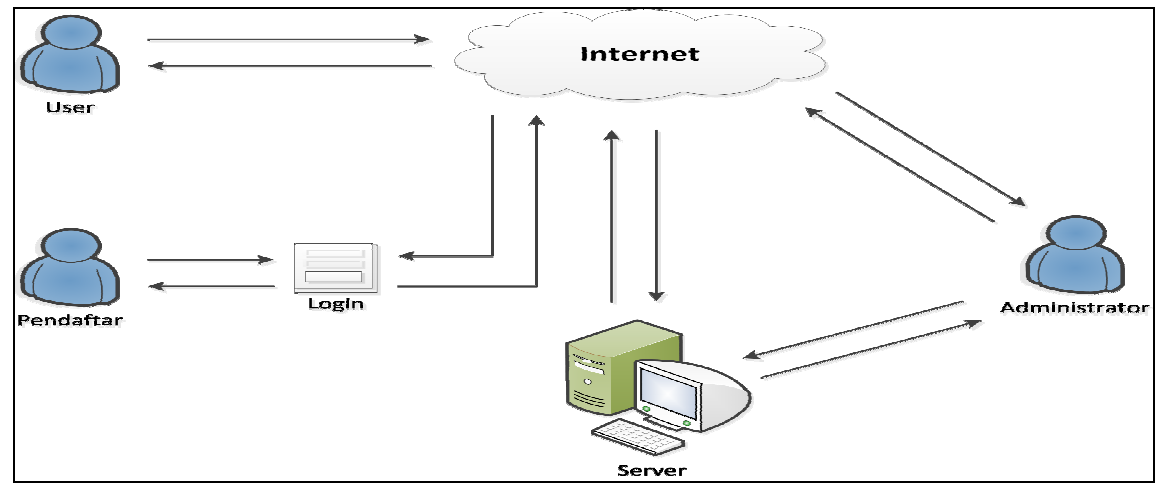

Gambar 1. Arsitektur Sistem

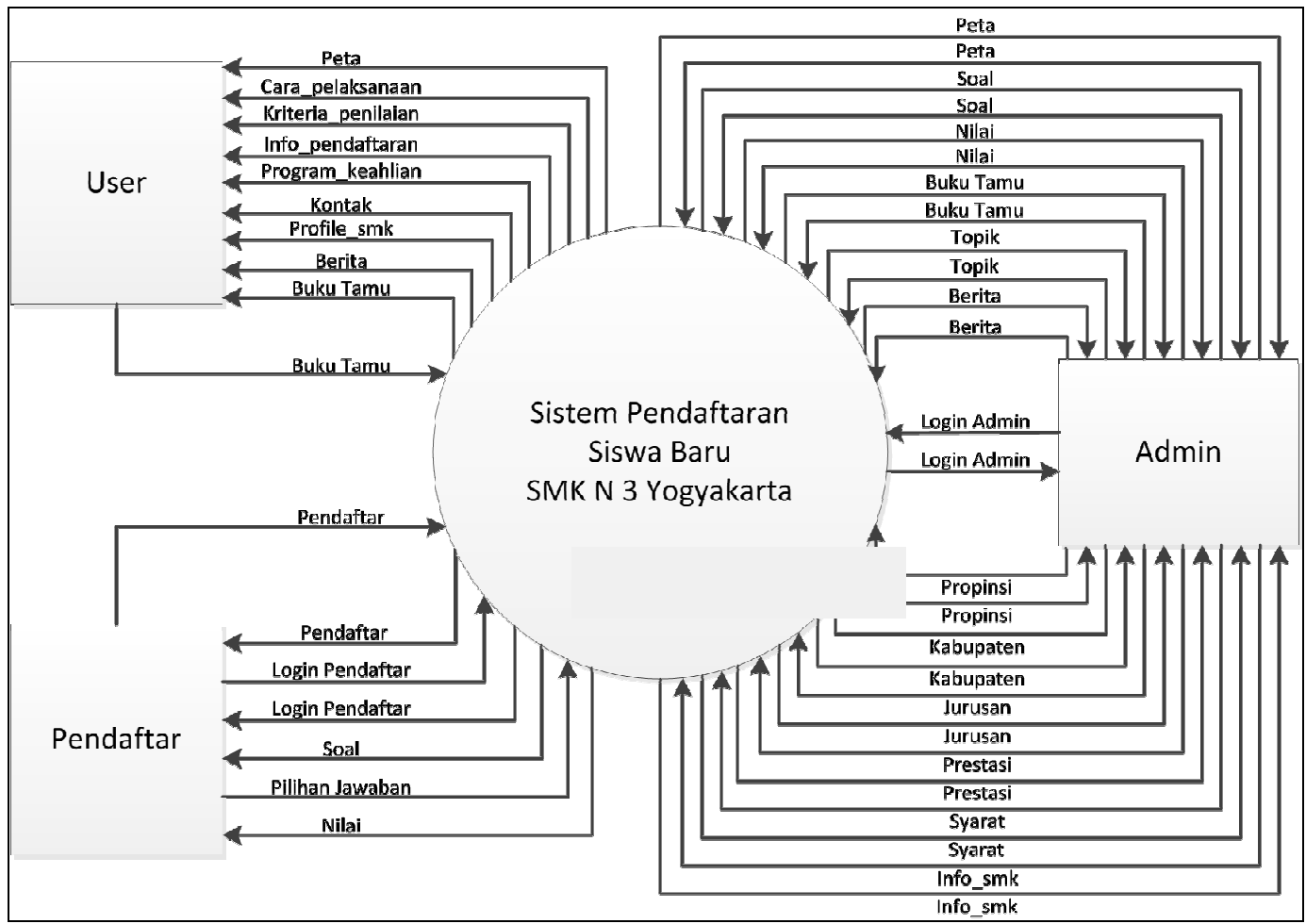

Gambar 2. Diagram Alir Data 


\subsection{Perancangan Basis Data}

Rancangan basis data diperlukan untuk membangun sistem basis data. Rancangan basis data berisikan Entity Relationship Diagram (ERD) terdiri dari komponen himpunan entitas dan himpunan relasi. Yang nantinya dipakai untuk mebangun tabel-tabel dalam Sistem Basis Data.

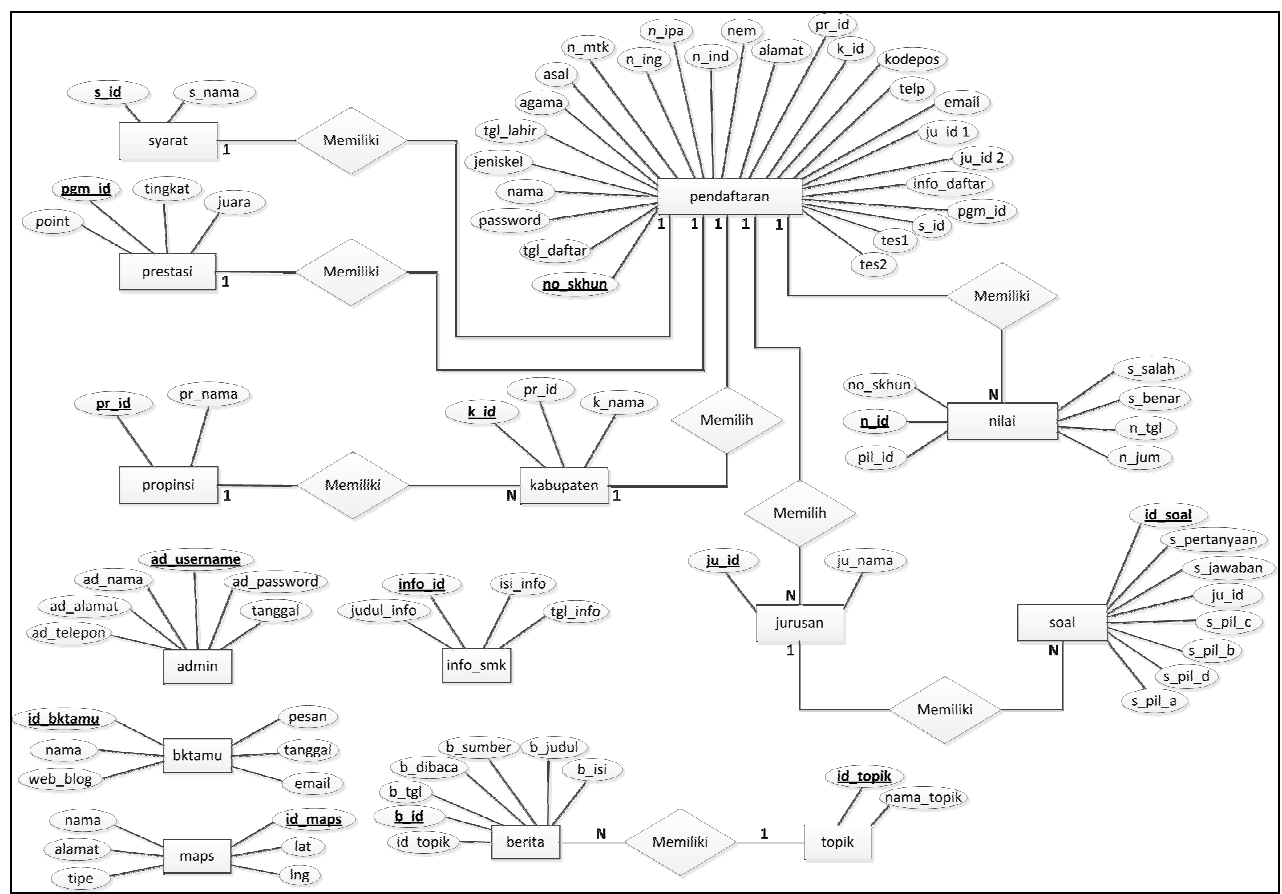

Gambar 3. Entitas Relation Diagram

\subsection{Perancangan User Interface}

Perancangan antarmuka (User interface) sangat diperlukan untuk pengembangan implementasi sistem yang akan dibuat sehingga memudahkan pengguna ataupun pengembang dalam mencapai hasil implementasi akhir yang diharapkan. User interface adalah sebuah media yang menghubungkan manusia dengan komputer agar dapat berinteraksi, ini dirancang untuk memudahkan pengguna dalam mengoperasikan sistem, sehingga pengguna paham apa yang harus dilakukan terhadap sistem.

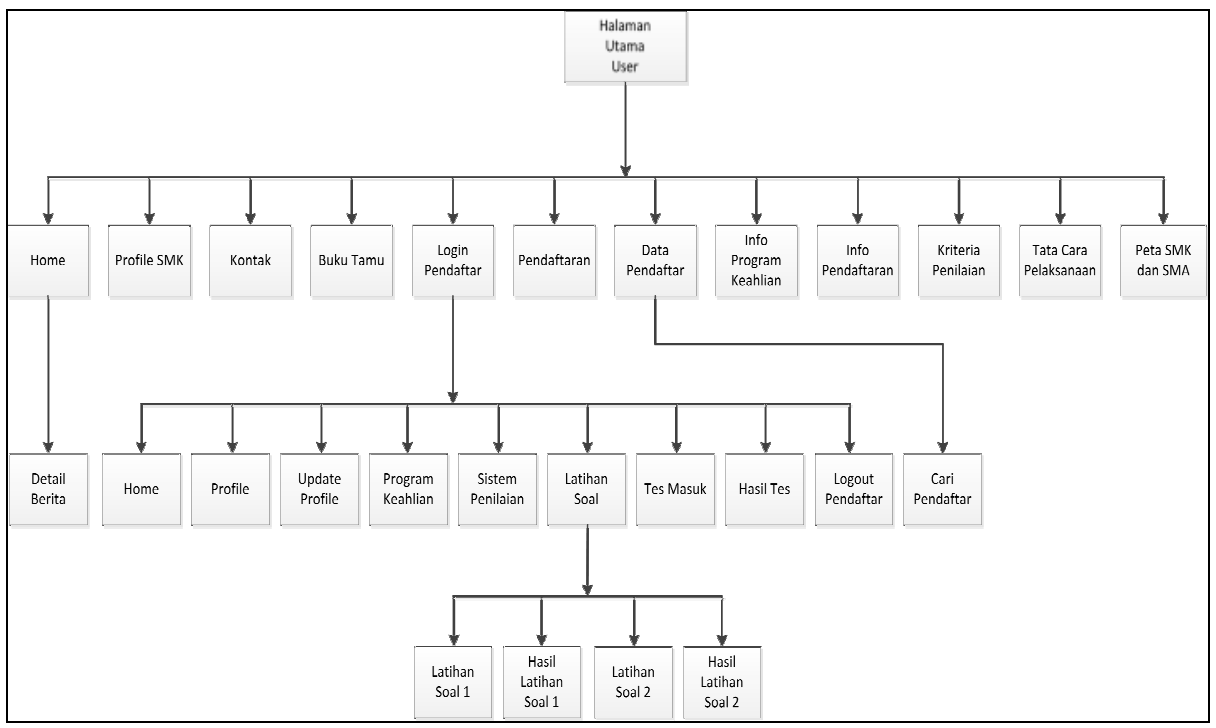

Gambar 4. Menu Utama User 


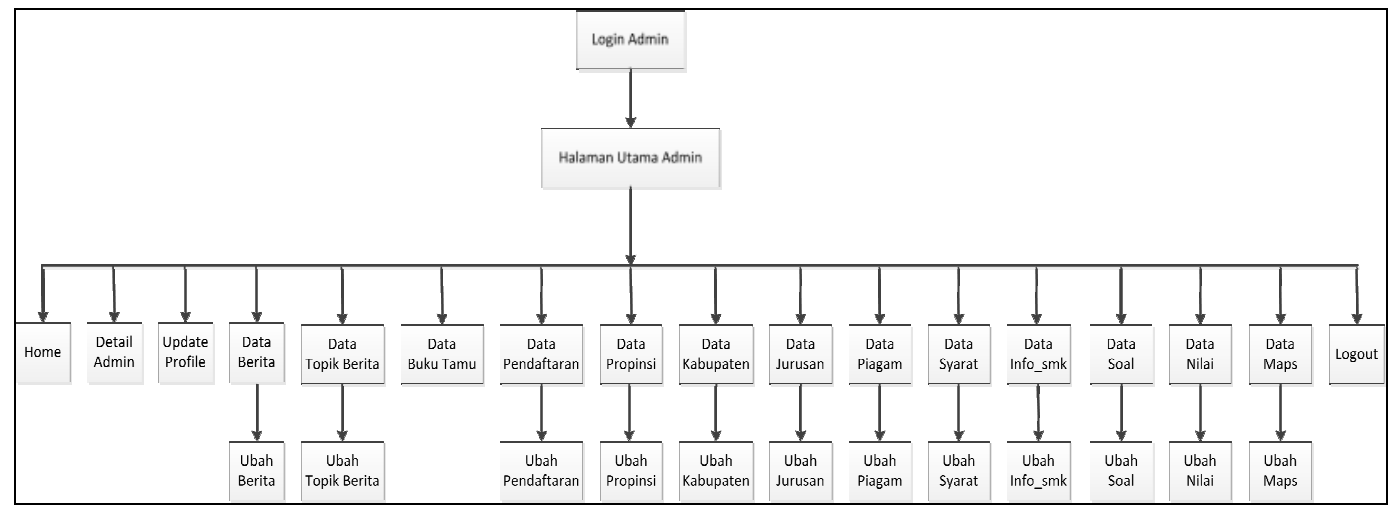

Gambar 5. Rancangan Menu Admin

\section{IMPLEMENTASI}

\subsection{Bagian Halaman User}

Bagian halaman user ini merupakan halaman yang berisi informasi-informasi yang bisa diakses secara umum oleh semua orang, seperti berita, buku tamu, informasi pendaftaran, informasi sekolah, data pendaftar dan yang lainnya. Berikut implementasi halaman pada bagian user:

1. Halaman home merupakan halaman awal saat memasuki web, isi utama dalam halaman home ini adalah cuplikan dari berita-berita yang berhubungan dengan jurusan pada SMK Negeri 3 Yogyakarta, seperti berita teknologi, berita otomotif dan yang lainnya.

2. Halaman kontak merupakan halaman yang digunakan untuk menampilkan data kontak SMK Negeri 3 Yogyakarta, selain itu juga terdapat informasi letak SMK Negeri 3 Yogyakarta yang ditampilkan dengan menggunakan Google Maps

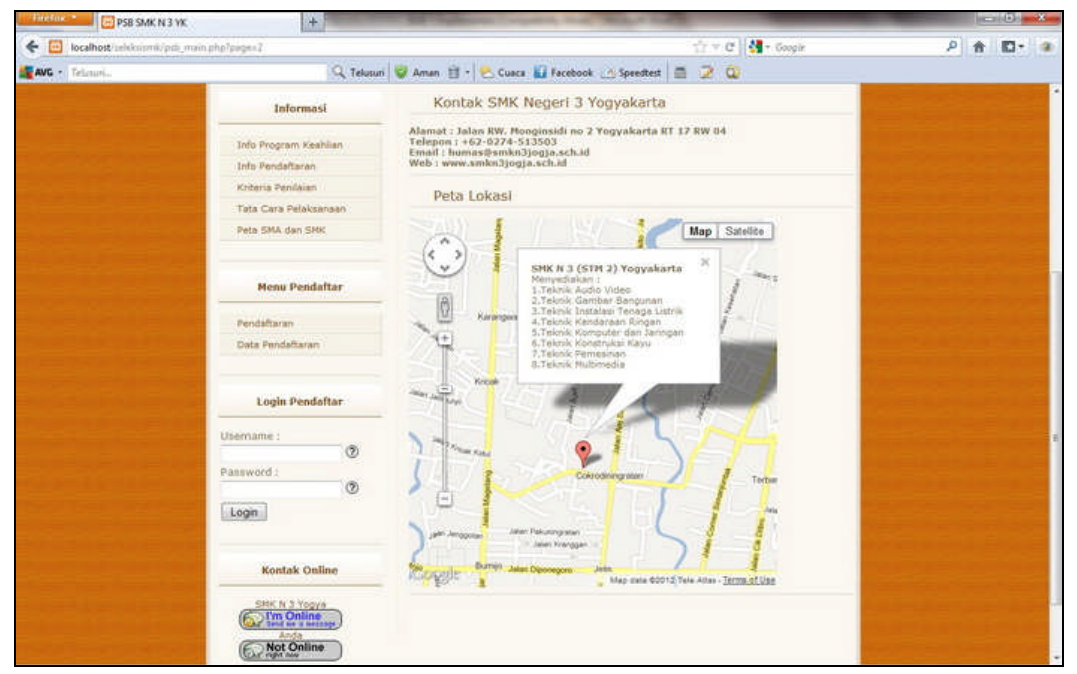

Gambar 6. Halaman Kontak

3. Halaman pendaftaran merupakan halaman yang berisi form-form yang wajib dilengkapi oleh seorang calon siswa baru yang ingin mendaftar pada SMK Negeri 3 Yogyakarta. Setelah mengisi lengkap semua form yang ada maka pendaftar akan secara otomatis terdaftar dan mendapatkan sebuah password dan username yang nantinya akan digunakan oleh pendaftar untuk masuk ke dalam halaman khusus pendaftar yang sudah terdaftar.( gambar 7)

4. Halaman data pendaftar merupakan halaman yang menampilkan data-data pendaftar yang sudah melakukan pendaftaran dan datanya sudah tersimpan ke dalam database. Namun data pendaftar tidak akan ditampilkan seluruhnya karena ada data yang bersifat pribadi, data pendaftar yang akan ditampilkan di dalam halaman ini adalah data nama, nem, syarat dan 
tanggal pendaftaran, dimana data akan diurutkan berdasar akumulasi nem tertinggi. Selain itu pada halaman ini juga terdapat proses pencarian yang dapat digunakan untuk mencari pendaftar, pada proses pencarian ini dapat digunakan no SKHUN ataupun nama pendaftar sebagai kata kunci untuk melakukan pencarian

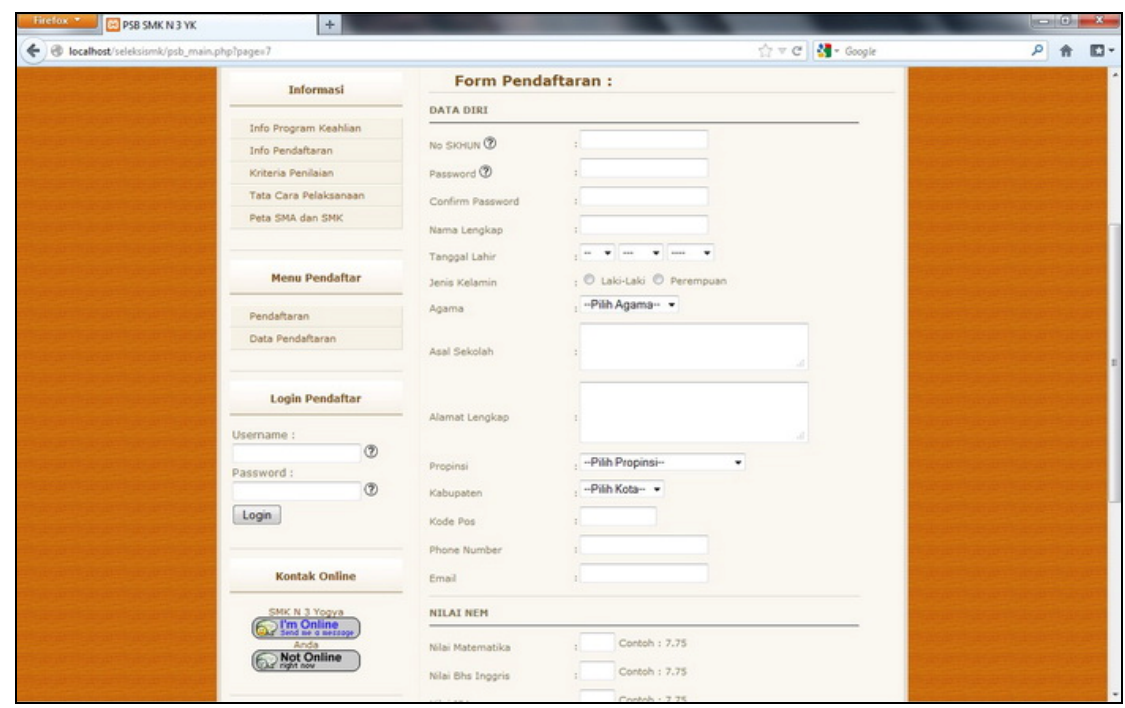

Gambar 7. Halaman Pendaftaran

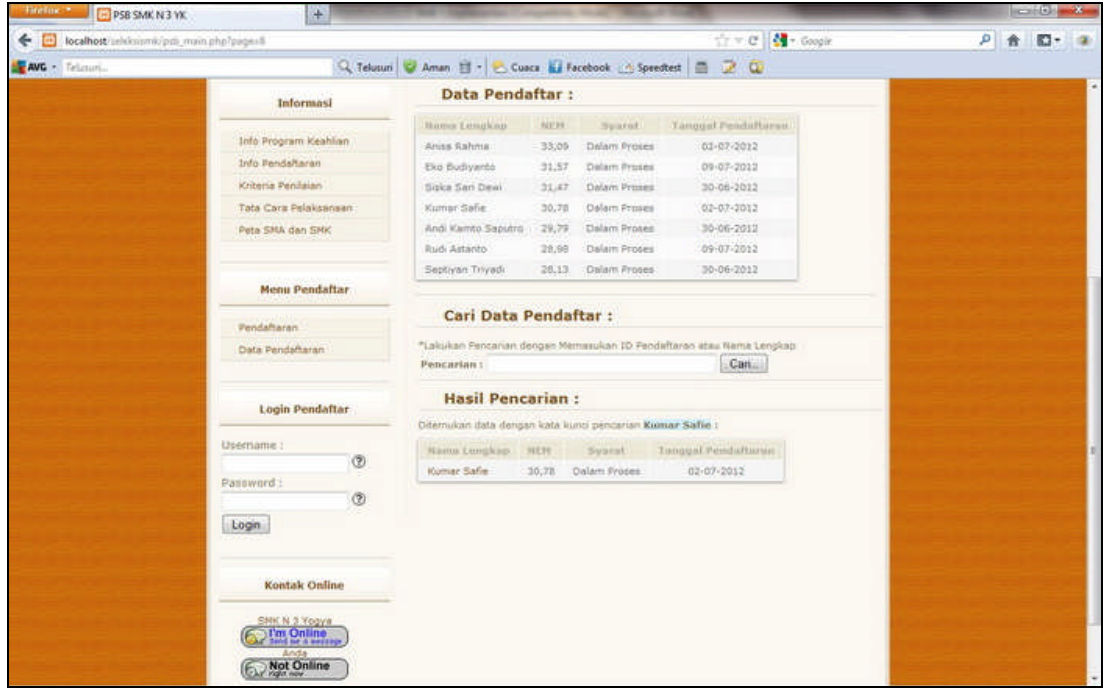

Gambar 8. Halaman Data Pendaftar

\subsection{Bagian Halaman Pendaftar}

Bagian halaman pendaftar ini merupakan bagian halaman yang khusus digunakan untuk pendaftar yang sudah melakukan registrasi melalui pendaftaran. Sehingga untuk bisa mengakses halaman ini memerlukan data login berupa username dan password. Pada bagian halaman pendaftar berisi halaman yang digunakan pendaftar untuk melakukan seleksi pendaftaran sesuai dengan jurusan yang sudah mereka ambil pada saat melakukan pendaftaran.

1. Halaman profile anda merupakan halaman yang digunakan untuk menampilkan profile detail mengenai pendaftar sesuai dengan data-data pada saat melakukan registrasi pendaftaran, data-data yang ditampilkan diambil dari data pendaftar yang disesuaikan dengan no skhun pendaftar yang digunakan sebagai username pada saat login, sehingga data-data yang ditampilkan akan sesuai dengan pendaftar yang telah melakukan login 
2. Halaman Latihan Soal merupakan halaman yang digunakan oleh calon siswa baru untuk melakukan pendalaman materi dengan cara mengerjakan latihan-latihan soal sesuai dengan jurusan yang mereka ambil, sehingga diharapkan para calon siswa baru dapat menyiapkan mental dalam mengahadapi tes ujian masuk.

3. Halaman Hasil Tes adalah halaman yang akan menampilkan hasil tes masuk. Selain itu halaman ini akan menampilkan nilai akumulasi, nilai akumulasi adalah merupakan nilai yang sudah terolah berdasarkan prosedur pembobotan untuk masuk ke SMK, setelah itu hasil dari nilai akumulasi nanti akan menentukan lebih cocok masuk ke jurusan mana seorang pendaftar

\subsection{Bagian Admin}

Halaman data pendaftaran merupakan halaman yang digunakan oleh admin untuk mengolah data pendaftaran dari para calon siswa baru yang sudah melakukan registrasi. Halaman ini admin dapat melihat data-data pendaftar, mengubah data pendaftar dan menghapus data pendaftar. Selain itu admin juga dapat memberikan beberapa status pada data pendaftar, seperti status pada pembayaran registrasi pendaftaran, dimana apabila seorang pendaftar belum melakukan registrasi pendaftaran maka seorang pendaftar belum diperkenankan untuk melakukan tes penjurusan baik yang pertama maupun yang kedua.

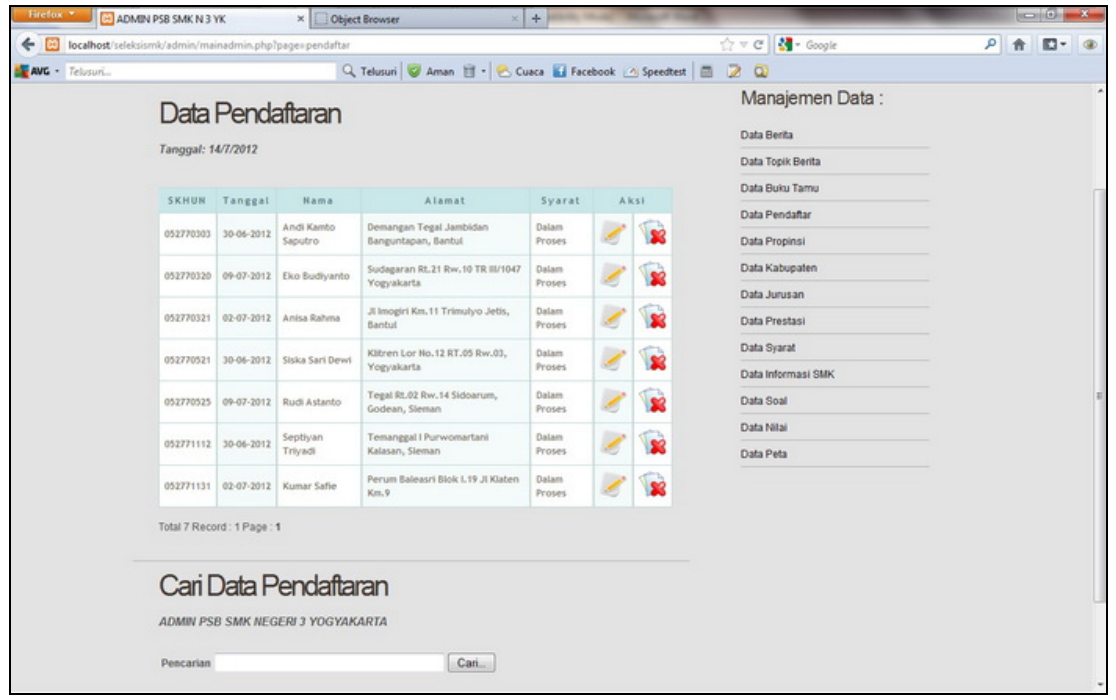

Gambar 9. Halaman Data Pendaftar

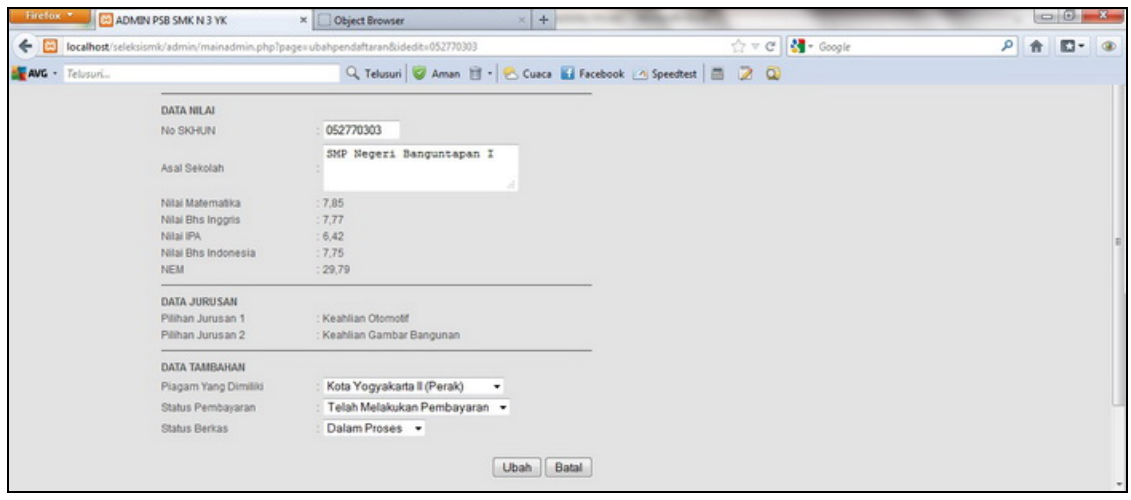

Gambar 10. Halaman Edit 


\section{KESIMPULAN}

Untuk meningkatkan kualitas pendidikan dan mutu penjaringan calon siswa baru, sehingga manajamen sekolah dapat melakukan pembaharuan didalam ujian masuk. Tujuan pembuatan website ini adalah untuk memudahkan orang tua dan siswa dalam melakukan pendaftaran tanpa harus datang ke sekolah.

\section{DAFTAR PUSTAKA}

Daihani, Dadan Umar, 2001, Sistem Pendukung Keputusan, Elex Media Komputindo, Jakarta Fathansyah, 2001, Buku teks Komputer basis Data, Bandung: Informatika Bandung

Nugroho, Adhi, 2008, Menjadi Administrator Basis Data Oracle 10g, Bandung : Informatika

Presman, Roger, 2002, Rekayasa Perangkat lunak Jilid 1, andi offset, Yogyakarta 